\title{
A young man with position-dependent erectile dysfunction: diagnostic work-up and interventional therapy of an arteriovenous malformation
}

\author{
Johannes Huber,' Hans H. Schild," Christian G. Huber, "'I Peter Hallscheidt, IV Markus Hohenfellner' \\ 'Department of Urology, University of Heidelberg, Germany. "Department of Radiology, University of Bonn, Germany. '"'Center for Psychosocial \\ Medicine, University Medical Center Hamburg-Eppendorf, Germany. ${ }^{\mathrm{IV}}$ Department of Radiology, University of Heidelberg, Germany.
}

Email: johannes.huber@med.uni-heidelberg.de

Tel.: $4906221-566110$

\section{INTRODUCTION}

With a prevalence of $5-20 \%$, erectile dysfunction (ED) is a very common disease compromising quality of life of the patient and his partner alike. ${ }^{1} \mathrm{ED}$ is mostly of multifactorial origin and principally psychogenic and organic causes can be discerned. Main risk factors are age, cardiovascular disease, smoking, depression and diabetes mellitus. Therefore, ED might indicate an early manifestation of general disorders and should thus be an inherent part in raising a medical history.

\section{CASE REPORT}

In May 2006, a 37-year-old man presented in our outpatient clinic with light ED that had prevailed since puberty. Penetration was possible only in a standing position, generally reaching nearly full erection. Lowering the upper part of the body caused the erection to become weaker and sexual intercourse was hardly possible. Selfadministered phosphodiesterase type 5 inhibitors did not show any effect on the position dependence. The patient was distressed by this situation.

In other respects, he was healthy and there was no evidence of psychosomatic etiology. The only abnormal finding in routine diagnostic investigation for ED consisted of congenital penoscrotal cavernous hemangioma (Figure 1a). As a vascular cause of the symptom was suspected, we performed MRI angiography after intracavernosal application of $10 \mu \mathrm{g}$ alprostadil (Figure 1b): a substantial arteriovenous malformation showed symmetrical draining towards the internal iliac veins. As a result, the penile arteries appeared rarefied.

A surgical approach was judged not promising and too risky. Therefore, we recommended selective percutaneous retrograde venoocclusive therapy, ${ }^{2}$ which was performed successfully in two sessions (Figure 1c). We assessed the International Index of Erectile Function (IIEF) ${ }^{3}$ and found a score of 18 at baseline, 21 at 3-months' follow-up and 18 at 24-months' follow-up (no ED at IIEF score $>21$ ). To objectify the functional changes we measured penis rigidity using

Copyright (c) 2011 CLINICS - This is an Open Access article distributed under the terms of the Creative Commons Attribution Non-Commercial License (http:// creativecommons.org/licenses/by-nc/3.0/) which permits unrestricted noncommercial use, distribution, and reproduction in any medium, provided the original work is properly cited.
RigiScan Plus ${ }^{\circledR}$ at baseline and 3-months' follow-up: ${ }^{4}$ after intracavernosal application of $10 \mu \mathrm{g}$ alprostadil and achieving maximal erection, data were acquired continuously while the patient alternated between standing and lying positions with a minimum episode duration of 5 minutes. As rigidity on the penile tip has proved to be the best overall predictor of erectile dysfunction, ${ }^{4}$ we used this parameter as our main outcome criterion. Values for all useable lying and standing intervals were compared by applying a paired samples t-test (Figure 2); $p<0.05$ was considered significant. At baseline, mean tip rigidity values differed significantly $(\mathrm{p}=0.038)$ while at 3 -months' follow-up differences were no longer significant $(\mathrm{p}=0.676)$. Although observed differences were small and there were no data on long-term test-retest reliability for Rigiscan ${ }^{\circledR}$ measurements, these results are consistent with the patient's subjective view. Rigidity had improved, especially in the distal part of the penis and was less dependent on body position. At 24-months' follow-up, the patient rated therapeutic success to be very satisfying, although the IIEF score had returned to the baseline score of 18.

\section{DISCUSSION}

We describe the diagnostic work-up and treatment outcome in a young patient with position-dependent ED due to an arteriovenous malformation. Hemangiomas are rarely found in the genitourinary tract $\mathrm{t}^{5-12}$ and cause ED in only a few cases, dependent on their hemodynamic properties. ${ }^{5}$ In this case, the congenital arteriovenous malformation drains arterious inflow directly to the internal iliac veins. Therefore, part of the arterial blood supply bypasses the corpora cavernosa and leads to a special form of venous leakage. However, the extent of the venous leakage and hence the erection rigidity depend on the intra-abdominal pressure, which alters with body position. For objectifying this anamnestic information and monitoring treatment outcome the Rigiscan ${ }^{\circledR}$ device proved helpful. It is one of the diagnostic measures recommended when cases remain ambiguous after basic investigation. ${ }^{1}$

Vascular conditions are the most common organic cause of ED. ${ }^{13}$ The vast majority of cases in this group result from metabolic changes, increasing with age owing to cardiovascular disease and diabetes mellitus. By far less common, but more important in younger men with ED are macroscopic arterial or venous pathologies, because once diagnosed, some of them can be treated causally. Patients with a history 

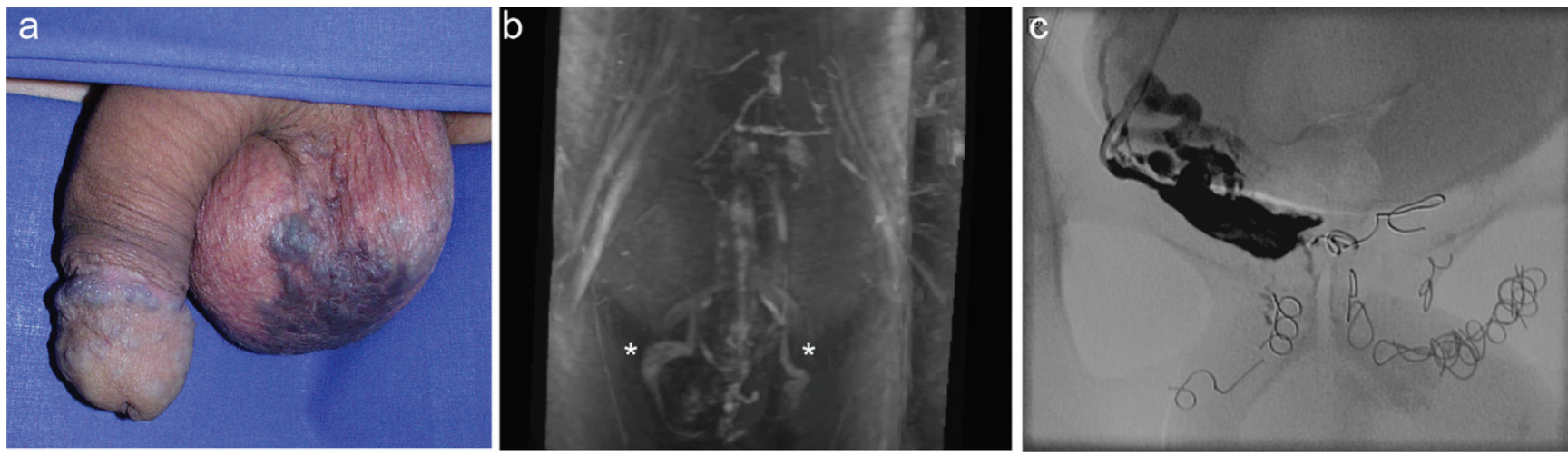

Figure 1 - a, Penoscrotal hemangioma; b, 3D-view of MRI-angiography showing venous leakage*; c, state after radiologic intervention.

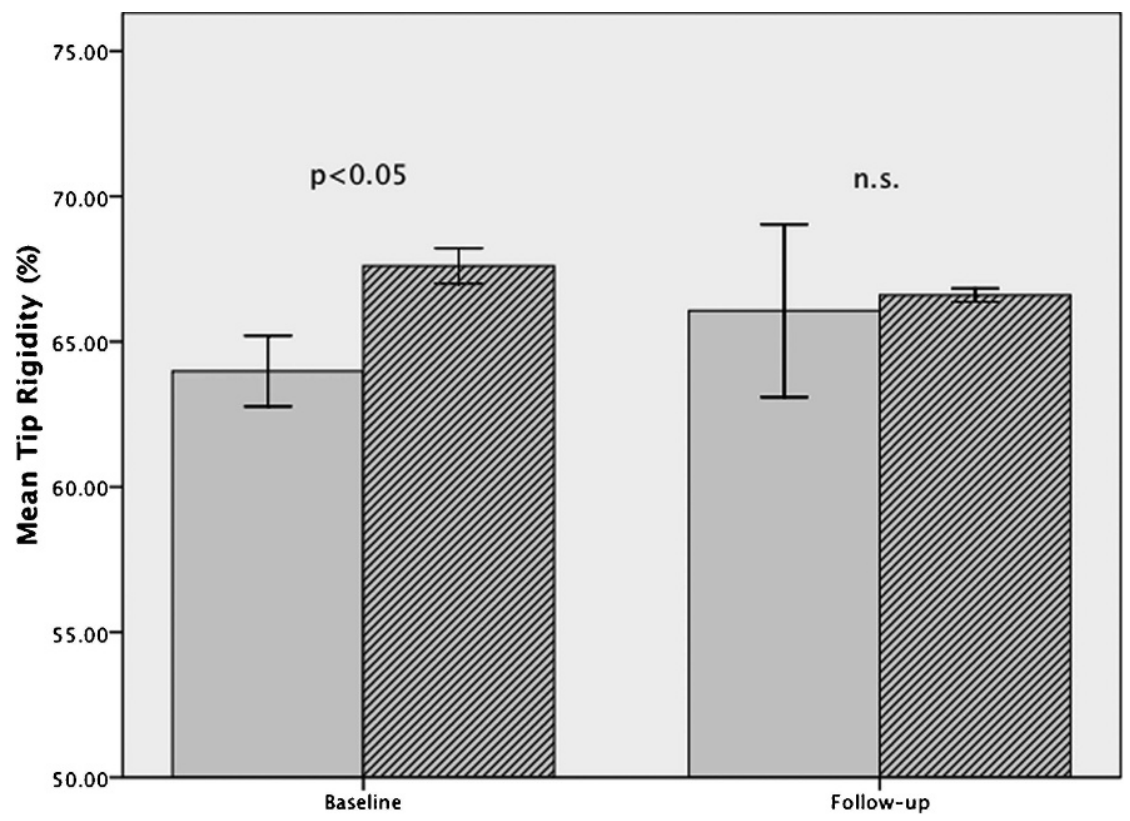

Figure 2 - Penis mean tip rigidity at baseline and at 3-months' follow-up in lying (left bars) and standing (right bars) position. Whiskers represent two standard deviations. n.s. = not significant.

of pelvic or perineal trauma causing arteriogenic ED can benefit from vascular surgery with a $60-70 \%$ long-term success rate. ${ }^{14,15}$ However, the results are entirely different concerning surgery for venous leakage. The various types of venous resection show discouraging long-term results and have therefore been abandoned in general. ${ }^{14}$ Only very occasionally, more durable improvements have been reported in highly selected patients. ${ }^{16}$ Because surgical treatment outcomes are limited, minimal invasive approaches like percutaneous embolization seem justified. This holds especially true as otherwise a penile prosthesis is the final option. ${ }^{17}$ After interventional venoablative treatment initial response rates are around $70-80 \%$, while lasting treatment success is found in $<30 \%$. The latter is mainly due to venous collateralisation. ${ }^{2,18,19}$

Limited long-term success has also been found in the reported case. Nevertheless, the subjective view of ED is not necessarily linked to objective measurements and our patient still feels satisfied.
Ethics committee approval: We performed all actions according to the "Declaration of Helsinki" in its latest version and respected usual data protection requirements. Ethics committee approval was not needed because the routine treatment of an individual patient is described. The patient is aware of the planned publication of his case. He agreed and documented his decision by signing a consent form after reading the manuscript including figures.

\section{REFERENCES}

1. Hatzimouratidis K, Amar E, Eardley I, Giuliano F, Hatzichristou D, Montorsi F, et al. Guidelines on male sexual dysfunction: erectile dysfunction and premature ejaculation. Eur Urol. 2010;57:804-14, doi: 10. 1016/j.eururo.2010.02.020.

2. Schild HH, Müller SC, Mildenberger P, Strunk H, Kaltenborn H, Kersjes W, et al. Percutaneous penile venoablation for treatment of impotence. Cardiovasc Intervent Radiol. 1993;16:280-6, doi: 10.1007/BF02629158.

3. Rosen RC, Riley A, Wagner G, Osterloh IH, Kirkpatrick J, Mishra A. The international index of erectile function (IIEF): a multidimensional scale for assessment of erectile dysfunction. Urology. 1997;49:822-30, doi: 10. 1016/S0090-4295(97)00238-0. 
4. Benet AE, Rehman J, Holcomb RG, Melman A. The correlation between the new RigiScan plus software and the final diagnosis in the evaluation of erectile dysfunction. J Urol. 1996;156:1947-50, doi: 10.1016/S00225347(01)65401-6.

5. Froehner M, Tsatalpas P, Wirth MP. Giant penile cavernous hemangioma with intrapelvic extension. Urology. 1999;53:414-5, doi: 10.1016/ S0090-4295(98)00444-0.

6. Nouira Y, Kbaier I, Attyaoui F, Menif E, Horchani A. Megapenis associated to corpus spongiosum agenesis with scrotal and pelvic hemangiomas. Eur Urol. 2001;40:571-4, doi: 10.1159/000049838.

7. Lin C-Y, Sun G-H, Yu D-S, Wu C-J, Chen H-I, Chang S-Y. Intrascrotal hemangioma. Arch Androl. 2002;48:259-65, doi: 10.1080/01485010290031565.

8. Skiadas V, Antoniou A, Primetis H, Moulopoulos L, Vlahos L. Intratesticular arteriovenous malformation. Clinical course, ultrasound and MRI findings of an extremely rare lesion on a 7 year follow-up basis. Int Urol Nephrol. 2006;38:119-22.

9. Ferrer FA, McKenna PH. Cavernous hemangioma of the scrotum: a rare benign genital tumor of childhood. J Urol. 1995;153:1262-4, doi: 10.1016/ S0022-5347(01)67582-7.

10. Zhao X, Zhang J, Zhong Z, Koh CJ, Xie HW, Hardy BE. Large renal cavernous hemangioma with renal vein thrombosis: case report and review of literature. Urology. 2009;73:443. e1-3, doi: 10.1016/j.urology. 2008.02.049.

11. Senoh H, Ichikawa Y, Okuyama A, Takaha M, Sonoda T. Cavernous hemangioma of scrotum and penile shaft. Urol Int. 1986;41:309-11, doi: $10.1159 / 000281225$
12. Jahn $H$, Nissen HM. Haemangioma of the urinary tract: review of the literature. Br J Urol. 1991;68:113-7, doi: 10.1111/j.1464-410X.1991. tb15276.x.

13. Kubin M, Wagner G, Fugl-Meyer AR. Epidemiology of erectile dysfunction. Int J Impot Res. 2003;15:63-71, doi: 10.1038/sj.ijir.3900949.

14. Wespes E, Wildschutz T, Roumeguere T, Schulman CC. The place of surgery for vascular impotence in the third millennium. J Urol. 2003;170:1284-6, doi: 10.1097/01.ju.0000086160.63566.11.

15. Munarriz R, Uberoi J, Fantini G, Martinez D, Lee C. Microvascular arterial bypass surgery: long-term outcomes using validated instruments. J Urol. 2009;182:643-8, doi: 10.1016/j.juro.2009.04.031.

16. Rahman NU, Dean RC, Carrion R, Bochinski D, Lue TF. Crural ligation for primary erectile dysfunction: a case series. J Urol. 2005;173:2064-6, doi: 10.1097/01.ju.0000158447.12163.f5.

17. Elhanbly S, Schoor R, Elmogy M, Ross L, Hegazy A, Niederberger C. What nonresponse to intracavernous injection really indicates: a determination by quantitative analysis. J Urol. 2002;167:192-6, doi: 10 . 1016/S0022-5347(05)65410-9.

18. Schild HH, Mildenberger P, Kersjes W. Effectiveness of platinum wire microcoils for venous occlusion: a study on patients treated for venogenic impotence. Cardiovasc Intervent Radiol. 1994;17:170-2, doi: 10.1007/BF00195515.

19. Fernández Arjona M, Oteros R, Zarca M, Díaz Fernández J, Cortes I. Percutaneous embolization for erectile dysfunction due to venous leakage: prognostic factors for a good therapeutic result. Eur Urol. 2001;39:15-9, doi: 10.1159/000052406. 